\title{
An observational study to find out the frequency of Gall Bladder Cancer in patients of gall bladder disease
}

\author{
Dr Sudershan Kapoor \\ Department of Surgery,Associate professor, Govt.Medical College,Amritsar,India
}

\begin{abstract}
The observational study is done to find out the frequency of gall bladder cancer in patients of gall bladder disease, found preoperatively or incidentally on biopsy of cholecystectomy specimen.

Methodology: The study was carried in surgery ward-6 of Guru Nanak Dev hospital attached to Govt. Medical College Amritsar in which 200 patients of gall bladder disease were studied and relative frequency of gall bladder cancer was noted.

Results: In our study, 200 patients of gall bladder disease during a period of 2 years were included. Out of these,20 patients were male while 180 were female. Maximum no of patients reported with Gall Bladder Disease were in age group 31-40 years. 7 patients out of 200 were diagnosed with carcinoma gall bladder,in which 6 were female and 1 was male with majority of patients presenting in the age group 61-70 years. Gall Bladder cancer constituted $8.2 \%$ of all Cancers in the body and $50 \%$ of all Gastrointestinal Tract cancers. 3 patients out of 7 diagnosed with Gall Bladder Cancer were diagnosed preoperatively and rest 4 were diagnosed incidentally on histopathological examination of biopsy specimen of gall bladder.

Conclusions: The frequency of Gall Bladder Cancer in our study is 3.5\%, with females out numbering males with $F / M$ ratio 6:1 and most of them presenting in the $5^{\text {th }}$ and $6^{\text {th }}$ decade of life. Gall Bladder Cancer was strongly associated with gall stones (100\%). Gall Bladder Cancer is the most common Gastrointestinal tract cancer.Most of the patients (57\%) presented with incidental diagnosis on HPE post cholecystectomy. $43 \%$ patients diagnosed preoperatively, were given neoadjuvent chemotherapy.
\end{abstract}

Keywords: Gall bladder,Cacer,Cholecystectomy, Gastrointestinal cancer,undifferentiated cancer

\section{Introduction}

Gall bladder cancer(GBC) was first described in 1777 by De Stoll. It is the most frequent malignant tumour of the biliary tract and fifth most common cancer of the digestive tract. In US and European countries, GBC accounts for less than $2 \%$ of all cancers reported annually. ${ }^{1}$ However in certain parts of the world it is a very common disorder, being relatively common in south Asian countries with India reporting an incidence rate of 3-10/100000. ${ }^{2}$ Highest incidence rate of Gall Bladder Cancer in the world is reported in chile and bilivia with highest mortality rate of both women (16.6/100000) and men(7.8/100000) also observed in chile. ${ }^{3}$ The association of Gall Bladder Cancer with gall stones increased the risk from 4-7 times than those without gall stones. ${ }^{4}$ The Gall Bladder Cancer has high prevalence in females with most of the women over 50 years of age and with concomitant gall stones. ${ }^{5}$ Besides gall stones, other factors such as pregnancy, female sex hormones, salmonella typhi, low fiber and vit A intake and high fat intake have been associated with Gall Bladder Cancer directly or indirectly. ${ }^{6}$ The commonest histological type of Gall Bladder Cancer is adenocarcinoma. ${ }^{7}$ This may be medullary, scirrhous, papillary or colloid. It appears that papillary form may have a better prognosis. Occasionally undifferentiated carcinoma, squamous cell carcinoma and carcinoma in situ may develop from non papillary adenomas of size more than $1 \mathrm{~cm}$ diameter. The asymptomatic nature of the disease always remained a problem in the diagnosis and treatment. Gall Bladder Cancer is always confused with other Gastrointestinal problems as it presents with vague symptoms. Thus urgent USG followed by biopsy is needed to diagnose it. Unfortunately in our setup most of the patients visit the hospital only when the disease is in advance stage and thus have poor prognosis.

\section{Methods}

An observation study was carried out at Govt. Medical College Amritsar/ Guru Nanak Dev Hospital, Amritsar, Surgery ward 6 of Dept. of surgery in which 200 patients of gall bladder disease from both OPD and emergency were studied for a period of 2 years (June 2009 to June 2011). Out of these 200 patients., 20 were male and 180 were female. 7 patients out of theses 200 patients were diagnosed with gall bladder cancer among which 3 were diagnosed pre operatively and 4 were incidentally diagnosed on biopsy of gall bladder specimen following cholecystectomy. 


\section{Gall Bladder Cancer Vs Total Cancers:}

\section{Results}

In our study Gall Bladder Cancer constituted 7 out of 85 cases $(8.2 \%)$ of the total number of cancer patients reported. Also Gall Bladder Cancer constituted 7 out of 14 cases $(50 \%)$ of the total Gastrointestinal tract cancers.


\section{Gall Bladder Carcinoma Vs Gall Bladder Disease:}

Out of the total 200 cases of Gall Bladder Disease, 7 were of Gall Bladder Cancer (3.5\%) and 193 were of cholecystitis (10\% acalculous cholecystitis \& $90 \%$ calculous cholecystitis)

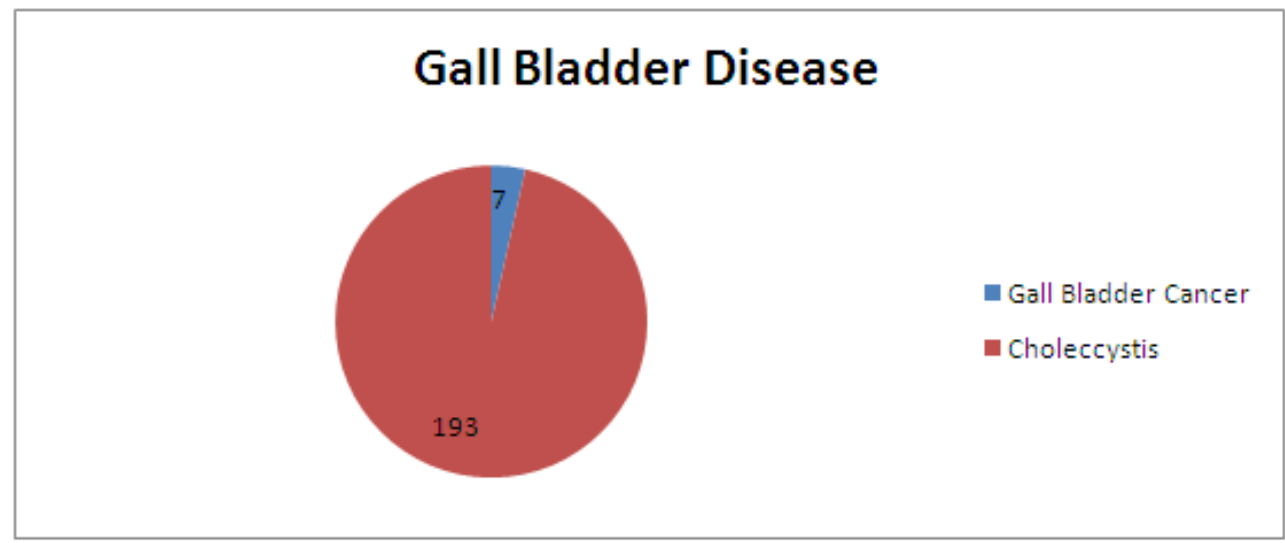

\section{Area Wise Distribution}

Considering the area wise distribution of Gall Bladder Disease, $70 \%$ cases (140/200) were from rural areas while considering the distribution of Gall Bladder Cancer, $85 \%$ cases $(6 / 7)$ were from rural areas.


\section{Sex Distribution}

The females appear to be more prone to both Gall Bladder Disease and Gall Bladder Cancer. Among total 200 cases of Gall Bladder Disease, 90\%(180) were female and 10\%(20) were male. Of the total 7 cases of Gall Bladder Cancer, 1(15\%) was male and $6(85 \%)$ were female with female/ male ratio 6:1. 


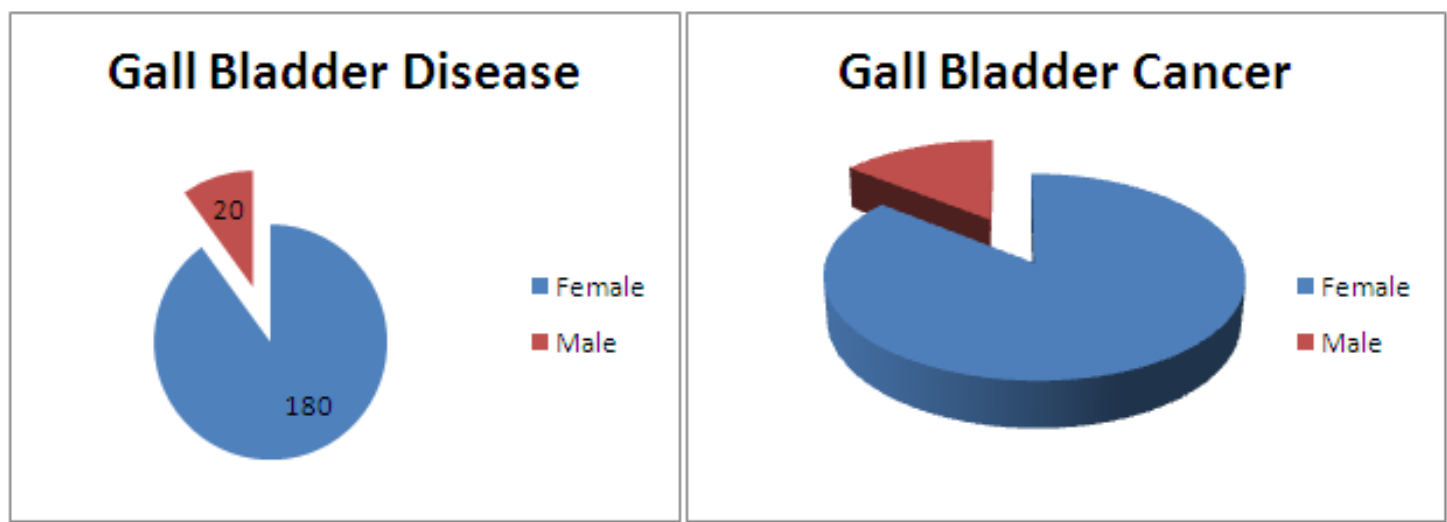

\section{Age Distribution}

Highest no. of patients presenting with Gall Bladder Disease were found in age group 31-40 years While the maximum number of Gall Bladder Cancer patients were found in age group 61-70 years (60\%).
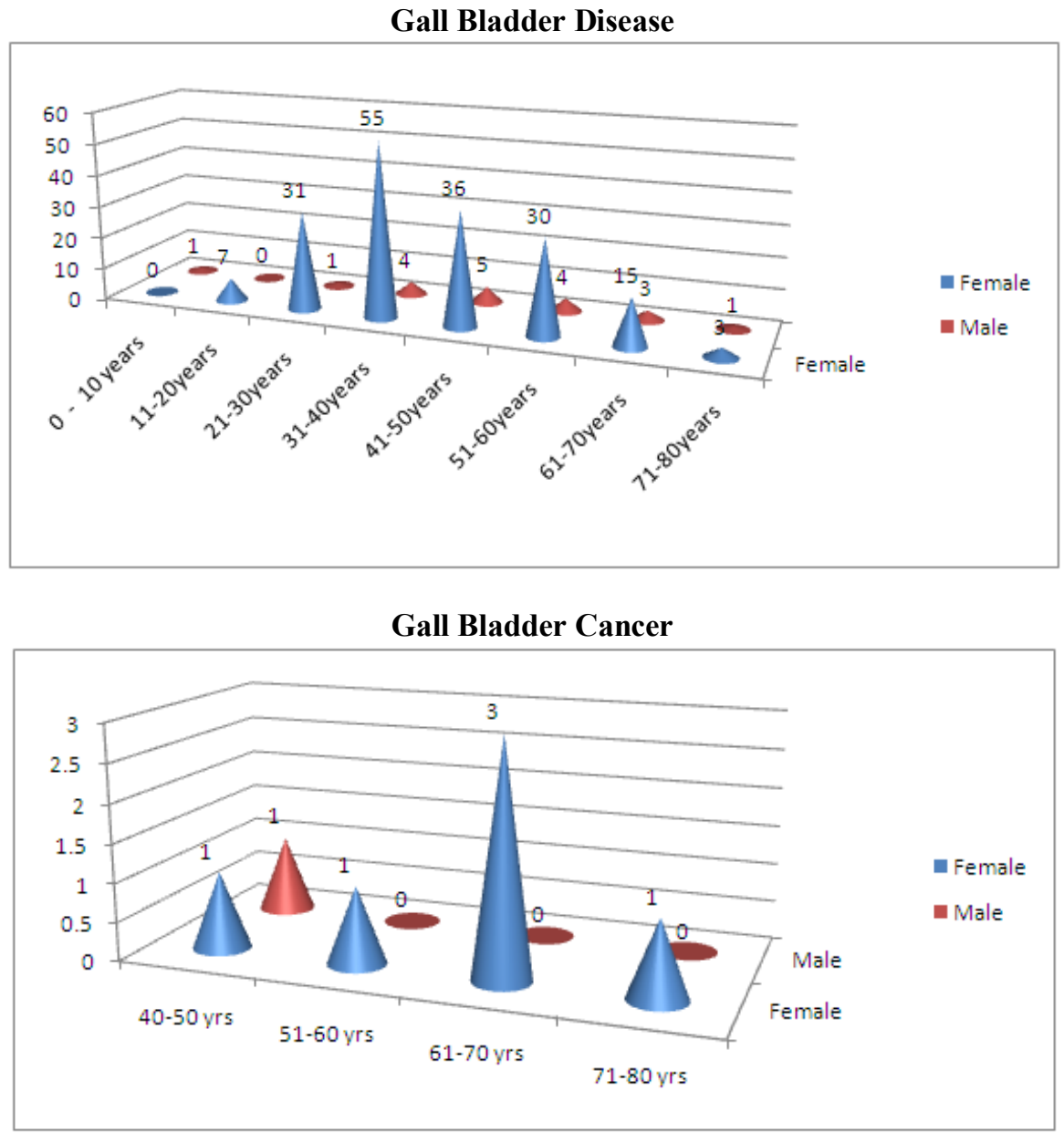

Preoperative Vs. Incidental GBC

Out of the total 7 cases of Gall Bladder Cancer, 3 (43\%) were reported preoperatively while $4(57 \%)$ were incidentally reported on histopathology examination of gall bladder specimen after cholecystectomy.Out of 3 preoperatively diagnosed patients of Gall Bladder Cancer, $2(66 \%)$ presented with Gall Bladder growth infiltrating to the liver with regional lymphadenopathy, while 1 (33\%) presented with growth confined to gallbladder only. 


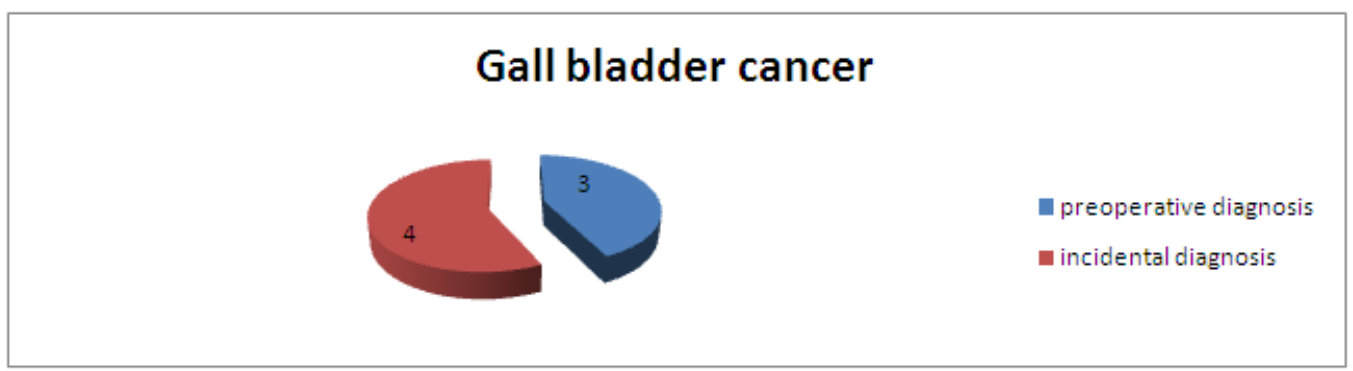

Calculus vs Acalculus gall bladder disease:

All our cases of gall bladder cancer were in patients of calculus cholecystitis and were of multiple stones of varying sizes.

\section{Neoadjuvant vs adjuvant chemotherapy:}

Out of the total 7 patients of GBC, 3(43\%) were given neoadjuvant chemotherapy with mitomycin c \& $5 \mathrm{FU}$, while 4 patients received adjuvant chemotherapy with the same regimen.

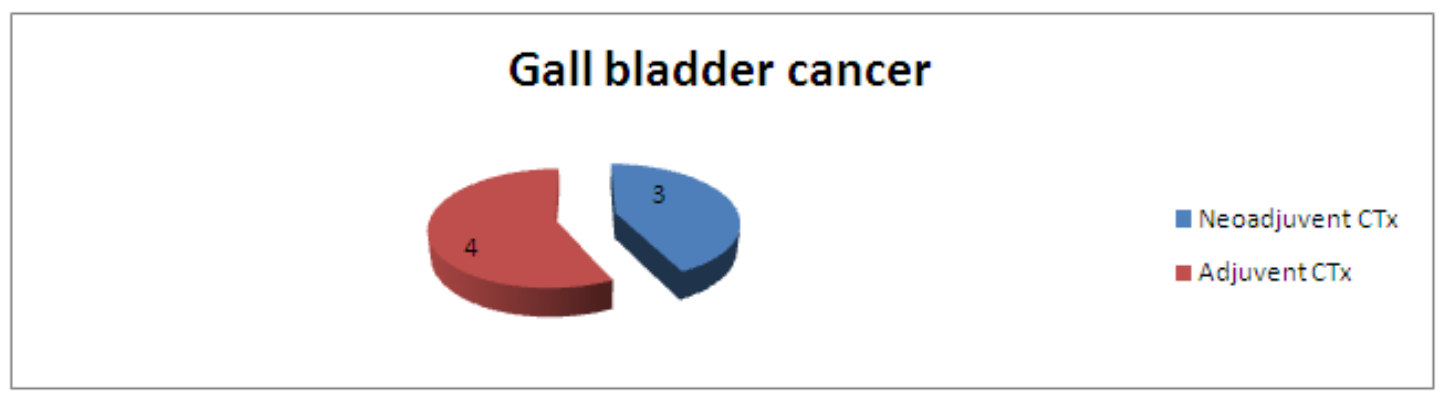

\section{Discussion:}

The Gall Bladder Cancer constitute $8.2 \%$ of total carcinomas and $50 \%$ of Gastrointestinal Tract Carcinomas in our study thus making Gall Bladder Cancer as the most common cancer in Gastrointestinal Tract and Fourth most common cancer in the body after Head and Neck, Carcinoma Breast and Carcinoma Cervix. This is in accordance with study conducted by parkash et $\mathrm{al}^{8}$ in Delhi which reported Gall Bladder Cancer as the Fourth most common cancer in the body and most common cancer among Gastrointestinal Cancers. The Gall Bladder Cancer constituted 3.5\% of the total cases of Gall Bladder Disease in our study. The frequency of Gall Bladder Cancer vary widely in different studies. Riaz and Ali $(1989)^{10}$ reported 2.7\%, Shah et al (1990) ${ }^{11}$ reported 6.6\%, Strauch $(1960)^{9}$ reported $1.4 \%$ and Hassan TJ $(1978)^{12}$ reported $1.6 \%$ frequency. In our study out of the total patients presenting with Gall Bladder Disease, $90 \%$ were female and $10 \%$ were male. Considering Gall Bladder Cancer in our study, out of 7 cases, $6(85 \%)$ were female and $1(15 \%)$ were male having F/M ratio : 6:1 which is higher when compared to other studies. This ratio was $3: 1$ in a study by mubarik et al ${ }^{13}$ and $1: 1.4$ to 4:1 in world literature ${ }^{14,15}$ Gall Bladder Cancer consisted of 3.5\% of all Gall Bladder Disease cases reported in our study and all cancer patients had associated cholelithiasis. This is in accordance with the study conducted by Wanebo HJ in which $60-90 \%$ cases of gall bladder cancer were associated with gall stones ${ }^{16}$. Age distribution of Gall Bladder Disease in our study show maximum incidence in the age group 31-40 years followed by 41-50 years. This is in accordance to the findings of a study by khuroo et $\mathrm{al}^{17}$ in which the median age of Gall Stone Disease in Indian population was recorded as 39 years compared to 52 years in western countries (Bates et al )$^{18}$.Thus incidence of Gall Bladder Disease is common in younger age group in India. Similarly maximum number of cases of Gall Bladder Cancer in our study were found in 61-70 years age group followed by 50-60 years which is slightly higher than the incidence in India recorded in studies by Prakash $\mathrm{AT}^{19}$ and Shukla $\mathrm{VK}^{20}$ and lesser than western counterparts i.e. UK $\left(70-74 \text { years) }{ }^{21} \text { and US (73 years) }\right)^{22}$. Nervi et al ${ }^{23}$ reported maximum incidence of Gall Bladder Cancer in age group 60-70years. This early occurance in Indian population may be due to early child bearing age and early presence of gall bladder disease. In our study $57 \%$ Gall Bladder Cancer were diagnosed incidentally on Histopathological examination of gall bladder specimen after cholecystectomy while $43 \%$ were diagnosed preoperatively.

\section{Conclusion:}

The data presented in this study reflects the frequency of Gall Bladder Cancer out of total Gall Bladder Disease cases in the last 2 years. The estimated incidence of the disease provide a glimpse of future trends of Gall Bladder Cancer. The study shows six fold increase in incidence among females and association of 
malignancy with gall stones which may reveal inflammatory and infective etiology. Every gall bladder specimen removed should be subjected to histopathology to rule out cancer. All cases of gall bladder disease with longer duration and with bigger stones should be investigated for cancer of gall bladder.Therefore early cholecystectomy for gall stones is the best way to prevent gall bladder cancer.

\section{Bibliography}

[1]. Greenlee RT, Hill-Harmon MB, Murray T, Thun M. Cancer Statistics 2001. Cancer J Clin 2001;51(1):15-36.

[2]. Panday M, Shukla M, Shukla V.Diet and Gall Bladder Cancer.Indian Journal of Medical and Pediatric Oncology 2008;29(1) 6-7.

[3]. Randi G.M Malvezzi, F. Levi, J.Ferlay, E. Negri, S. Franceschi, La Vecchia C. Epidemiology of biliary tract cancers: an update . Annals of Oncology 2009; 20:146-159.(s)

[4]. Nervi F., Duarte I., Gomez G, Rodriguez G, Pino G D, Ferrerio O et. Al. Frequency of gall bladder cancer in Chile, a high risk area. International Journal of cancer, 1988; (41) 657-660.(s)

[5]. Ahmad M, Khan AH, Mansoor A. The pattern of malignant tumors in Northen Pakistan J Pak Med Assoc 1991;41:270-73

[6]. Rizvi TJH, Zuberi SJ. Risk factors for gallbladder cancer in Karachi. J Ayub Med Coll Abottabad 2003;15(3):16-8.

[7]. Chaudhary MA, Ahad A, Durrani KM, Akbar J. Carcinoma of gallbladder. Proceeding SZPGMI 1989;

[8]. Prakash AT, Sharma LK, Pandit PN. Primary carcinoma of the gallbladder. Br J Surg 1975; 62:33-6.

[9]. Strauch GO, Providence RI. Primary carcinoma of gallbladder. 10 years cummulative review of American Literature Surgery 1960;47:368.

[10]. Riaz S, Ali A. Carcinoma of the gallbladder Pak J Med. Res. 1989;28:267-269.

[11]. Shah SA et al. Gallstone disease in Pakistan .The J Surg. 1990;! :30-33.

[12]. Hassan TJ, Zuberi SJ, Maqsood R. Carcinoma of the gallbladder. JPMA 1978;28:33.

[13]. Mubarik A, Mansoor A, Khan AH. Carcinoma of gallbladder. A study of 112 consecutive cases. Pak. A.F. Med. J 1990; XL 111:1 7.

[14]. Yamaguchi K, Enjoji M. Carcinoma of gallbladder. Am J Surg 1992;163 :382

[15]. Yamaguchi K, Chijiwa K, Nishihara K, Takashima M, Kawakami K, Tanaka M. Retrospective analysis of 70 operations for gallbladder carcinoma. Br J Surg 1997:84:200-4.

[16]. Wanebo HJ Carcinoma of the gallbladder. InWanebo H.J. (ed) Hepatic \& biliary cancer. New York Marcel Decker 1987:448-450.

[17]. Khuroo MS, Mahajan R, Zargar SA, Javid G, Sapru S. Prevalence of biliary tract disease in India: A sonographic study in adult population in Kashmir. Gut 1989;30:201-5.

[18]. Bates T, Harrison M, Lowe D, Lawson C, Padley N. Longitudinal study of gall stone prevalence at necropsy. Gut 1992;33:103-7 .

[19]. Prakash AT, Sharma LK, Pandit PN. Primary carcinoma of the gallbladder. Br J Surg 1975;62:33-6.

[20]. Shukla VK, Khandelwal C, Roy SK, Vaidya MP. Primary carcinoma of the gall bladder: A review of a 16 -year period at the University Hospital. J Surg Oncol 1985;28:32-5.

[21]. Carty NJ, Johnson CD. Carcinoma of the gall bladder: A survey of cases in Wessex 1982-1989. J Royal Coll Surg Edinb 1991;36:238-41.

[22]. Carriaga MT, Henson DE. Liver, gallbladder, extrahepatic bile ducts, and pancreas. Cancer 1995;75(Suppl 1):171-90.

[23]. Nervi F, Durate I, Gomez G, Rodriguez G, Del Pino G, Ferrerio O, et al. Frequency of gall bladder cancer in Chile, a high-risk area. Int J Cancer 1988;41:657-60. 